CEWP 20-09

\title{
Covid-19, Family Stress and Domestic Violence: Remote Work, Isolation and Bargaining Power
}

\author{
Louis-Philippe \\ Beland \\ Carleton University \\ Abel Brodeur \\ University of \\ Ottawa \\ Joanne Haddad \\ University of \\ Ottawa
}

June 2020; revised 5 June 2020

\section{CARLETON ECONOMICS WORKING PAPERS}
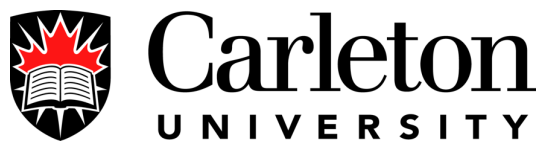

Department of Economics

1125 Colonel By Drive

Ottawa, Ontario, Canada

K1S 5B6 


\title{
Covid-19, Family Stress and Domestic Violence: Remote Work, Isolation and Bargaining Power*
}

\author{
Louis-Philippe Beland Abel Brodeur Joanne Haddad Derek Mikola \\ June 5th, 2020
}

\begin{abstract}
We study the impacts of COVID-19 on domestic violence and family stress. Our empirical analysis relies on a unique online survey, the Canadian Perspective Survey Series, which allows us to investigate the mechanisms through which COVID-19 may affect family stress and domestic violence. We find no evidence that changes in work arrangements are related to self-reported levels of family stress and violence in the home due to confinement, suggesting that remote work on a large scale does not lead to family violence. In contrast, we find that the inability to meet financial obligations and maintaining social ties significantly increase reported family stress and domestic violence. These findings are consistent with two alternative mechanisms: social isolation and decreased bargaining power for women. Last, we provide suggestive evidence that receiving financial relief does not mitigate the effect of financial worries on domestic violence and family stress. We conclude that targeted programs supporting victims of domestic violence may be more effective.
\end{abstract}

KEYwORDS: COVID-19, lockdown, domestic violence, family stress, isolation and remote work.

JEL CODES: D03, I18, J12.

\footnotetext{
*Beland: Carleton University; louisphilippe.beland@carleton.ca. Brodeur: University of Ottawa; abrodeur@uottawa.ca. Haddad: University of Ottawa; jhadd086@uottawa.ca. Mikola: Carleton University; derekmikola@cmail.carleton.ca. We would like to thank Harold Kim from the Centre for Social Data Integration and Development, Social, Health and Labour Statistics Field (CSDID) at Statistics Canada for clarifying information on the data used. We would also like to thank Stephanie Armbruster and Frances Woolley for heplful comments on the draft.
} 


\section{Introduction}

The surge in domestic violence incidents due to COVID-19 has been discussed widely in the media in several countries. The alleged causes of increasing domestic violence range from lockdowns, remote work, social isolation, and economic distress. For instance, the NY Times recently cited the founder of a foundation helping victims of domestic violence:

"We've been getting some very distressing calls, showing us clearly just how intense psychological as well as physical mistreatment can get when people are kept 24 hours a day together within a reduced space."1

Isolation might only be a contributing part of the increase in domestic violence. Economic factors such as being laid-off or working from home are thought to increase the domestic violence rates as stress and interactions within families increase. ${ }^{2}$

"As the worldwide pandemic spawns mass quarantines, dire income loss and uncertainty, experts cautioned that all these conditions can intensify stress and abuse in homes where violence already existed or was imminent." 3

There are several potential reasons as to why one might expect a rise in heated arguments and domestic violence during the pandemic. One plausible mechanism is social isolation, wherein COVID-19 increased women's vulnerability to violence through changes in work arrangements and mandatory confinement measures trapping some women inside their home. The lack of social and physical contact with families, friends, coworkers, and protection services may have intensified their isolation and reduced the societal protection (e.g., Gelles (1983); and Gelles and Straus (1979)). ${ }^{4}$ A second possible mechanism is a decrease in bargaining power for women due to increasing unemployment and financial distress. A simple intra-household bargaining model suggests that domestic violence incidents increase when the relative labour market outcomes of women worsen (Aizer (2010); Anderberg et al.

\footnotetext{
${ }^{1}$ https://www . nytimes.com/2020/04/06/world/coronavirus-domestic-violence.html

${ }^{2}$ The impacts of COVID-19 on the labour market has been documented in Canada, Europe, and the U.S. (e.g., Beland, Brodeur, Mikola and Wright (2020); Lewandowski (2020); Beland, Brodeur and Wright (2020); Gupta et al. (2020)), with large increases in unemployment.

${ }^{3}$ https://www theglobeandmail.com/canada/article-self-isolation-directives-increase-risk-for-women-facing-don

${ }^{4}$ Domestic violence is also an issue facing women affected by natural disasters. Previous studies documented a positive relationship between domestic violence and natural disasters in both developing and developed countries (e.g., Anastario et al. (2009); Enarson (1999); Parkinson and Zara (2013)).
} 
(2016)). An alternative mechanism is related to a decrease in employment and an increase in work-from-home due to COVID-19. This can increase the time partners spend together and result in intimate partner violence.

Understanding the precise mechanisms through which COVID-19 might affect family violence is key for policymakers. If domestic violence occurs solely because of social isolation, expanding programs like women's shelters and helplines may be an effective policy. If domestic violence occurs because of social isolation due to financial reliance on their partner, policies which expand labour market opportunities may give greater financial autonomy while not directly targeting social isolation. In other scenarios, where women may not work or seek help in public, it may be best to decrease the opportunities for men to be at home or improve economic opportunities. Any combination of the aforementioned scenarios may be present and this paper attempts to rule out competing theories for focused and effective policy. We discuss several mechanisms through which COVID-19 could affect domestic violence: social control and isolation, emotional cues, and intra-household bargaining power.

Our paper is the first, to our knowledge, which attempts to test and disentangle the mechanisms through which COVID-19 may affect family stress and domestic violence. We rely on a unique survey, the Canadian Perspective Survey Series, to investigate how the pandemic might affect self-reported perceived risk of domestic violence and family stress. This online survey was conducted from March 29, 2020 to April 3, 2020 using a random sample of households from Statistics Canada's Labour Force Survey (LFS) and include questions about the effect of COVID-19 and confinement on family stress, domestic violence, worries about financial obligations, remote work and other relevant socioeconomic variables. Importantly, respondents did not know that the survey would include questions about family stress or violence in the home prior to their participation. Our study and findings may therefore be more representative of the entire population than surveys specifically targeting victims of domestic violence. Moreover, the Canadian context is useful in discussing theories of social isolation since all provinces had stopped educational services and declared emergencies which restricted social and business interactions before our survey.

Our results suggest that employment status and work arrangements such as working from home are not related to women's perceived impacts of COVID-19 on family stress and 
domestic violence. ${ }^{5}$ This last result suggests the large increase in remote work is not driving the rise in domestic violence. In contrast, our results suggest that women's inability to meet financial obligations significantly increase reported family stress and domestic violence. Our estimates are large and statistically significant at conventional levels, and suggest that women who report a perceived major impact of COVID-19 on their ability to meet their financial obligations or essential needs are 52 and 29 percent of a standard deviation more likely to report higher levels of family stress due to confinement and domestic violence in comparison to those reporting no perceived impact, respectively. These findings are consistent with a simple intra-household bargaining model in which expected future earnings affect the risk of domestic violence for women (e.g., Aizer (2010)).

In addition to documenting higher perceived risks of domestic violence for women with high levels of financial worries, we can offer a new perspective on the impact of social isolation on family violence. For this analysis, we rely on a question about the impacts of COVID-19 on women's ability to maintain social ties. We find that an increase in women's concern about maintaining social ties is positively associated with concerns regarding domestic violence and family stress from confinement. These results are consistent with prior research which shows women's social isolation decreases the perpetrator' costs of domestic violence and increases the incidence (e.g., Gelles (1983); Gelles and Straus (1979)); Usher et al. (2020)).

We furthermore provide suggestive evidence that receiving financial relief for financial obligations which cover rent (or mortgage) payments, car payments or other household bills, does not alleviate the impact of financial obligation pressures on perceived family stress and violence in the home. We briefly discuss policy recommendations in the conclusion.

We contribute to a growing literature on the effects of COVID-19 on mental health, wellbeing and domestic violence (Boserup et al. (2020); Brodeur et al. (2020); Hamermesh (2020); Payne et al. (2020); Tubadji et al. (2020)). Two relevant papers using police calls and helpline contacts are Leslie and Wilson (2020) and Armbruster and Klotzbucher (2020), respectively. Leslie and Wilson (2020) provide evidence that COVID-19 and lockdowns in the US had led to a large increase in domestic violence calls. Armbruster and Klotzbucher (2020) provide

\footnotetext{
${ }^{5}$ We use interchangeably domestic violence and family violence in the text. Our question refers to family violence and can refer to any act committed by a family member or intimate partner against another member of the family.
} 
evidence that helpline contacts increased in Germany by around $20 \%$ in the week following the implementation of the lockdown reflecting heightened loneliness, anxiety, and suicidal ideation. We contribute to this growing literature by showing that the pandemic affects domestic violence and family stress through increasing financial worries, rather than work arrangements or employment status. Moreover, we document that social isolation through increased concern about maintaining social ties affects domestic violence and family stress.

Last, we contribute to a growing literature on the impacts of COVID-19 on gender equality (e.g., Alon et al. (2020)), the supply of and demand for child care (e.g., Ali et al. (2020); Sevilla and Smith (2020)) and fertility (Schwandt (2020)).

The rest of the paper is structured as follow. In section 2, we briefly discuss the COVID19 pandemic in Canada. Section 3 discusses channels through which the pandemic could affect family well-being and violence in the home. Section 4 describes the data set and our empirical model. In section 5, we present our findings. The last section concludes.

\section{COVID-19 and Domestic Violence in Canada}

Canada has been no exception to the global pandemic caused by COVID-19 which as of June 4th, 2020, has caused over 7,500 deaths and 93,000 confirmed cases of the more than 1.75 million individuals tested. ${ }^{6}$ Provincial governments closed public schools and ordered a shutdown of businesses which were not deemed essential by mid-March. Additional policies such as restricting the size of public and private gatherings and enforcing social and physical distancing laws were simultaneously rolled out.

On March 18th, the Federal government provided the first announcement for Canada's COVID-19 Economic Response Plan: Support for Canadians and Businesses. This includes support directly to individuals and businesses primarily aimed at reducing the negative shortrun effects anticipated by all due to COVID-19. Additional major policies subsequently added to the Economic Response Plan by the Federal government include the Canada Emergency Response Benefit (CERB), Canada Emergency Wage Subsidy (CEWS) and the Canada Emer-

\footnotetext{
${ }^{6}$ See https://www. canada.ca/en/public-health/services/diseases/2019-novel-coronavirus-infection. html?topic=tilelink for updated information.
} 
gency Student Benefit (CESB). ${ }^{7}$ Still, these policies were met with severe increases in the unemployment rate of Canadians, which rose to $13 \%$ in April 2020, a further increase from 7.8\% in March 2020 and 5.6\% in February 2020 (Beland, Brodeur, Mikola and Wright (2020)).

According to Statistic Canada, during 2018, there was 99,000 reported incidents of intimate partner violence offences in Canada and 60,651 reported incidents for child and youth victims (aged 17 and younger) of police-reported family violence in Canada. ${ }^{8}$ Reports in the media documents significant increase in domestic violence incidents due to COVID-19 (e.g., Patel (2020)).

\section{Family Stress and Domestic Violence}

In this section, we discuss several mechanisms through which COVID-19 could affect domestic violence: social control and isolation, emotional cues, and intra-household bargaining power.

\subsection{Social Control and Isolation}

The pandemic outbreak resulted in lockdowns and stay-at-home orders which likely increased women's social isolation, and made it much harder to (temporarily) escape violent partners (Usher et al. (2020)). The theory of social control developped in sociology and applied to intimate partner violence (e.g., Gelles (1983), and Gelles and Straus (1979)) predicts that societal controls and protection can increase the perpetrator' costs of domestic violence and reduce incidence. Sanctions include formal police interventions (Iyengar (2009); Nye (1958); Wells and Rankin (1988)) and informal societal disapproval of friends and relatives (Farmer and Tiefenthaler (1997)). Domestic violence becomes thus more common when friends and relatives outside of the family are incapable of serving as agents of social control (Gelles (1993)). Therefore, a lack of attachment to other individuals outside the family and thus an increase in social isolation, induces the possibility of spousal violence (Gelles (1983)). ${ }^{9}$

\footnotetext{
${ }^{7}$ The CERB provides short-term income support for those individuals displaced in the labour market due to COVID-19. CEWS provides businesses with temporary wage subsidies in hopes to retain workers. The CESB provides income support to those in, finishing, or beginning, post-Secondary education since many of these individuals may not qualify for CERB.

${ }^{8}$ For additional statistics, see Shana Conroy and Savage (2019).

${ }^{9}$ The literature on social control is vast, see also Alesina et al. (Forthcoming); Browne (1987); Cazenave and Straus (1979); Carlen (1983); Eaton (1986); Gelles (1983); Gelles (1993); Stets and Straus (1990); Walker (1989).
} 
Our results provide evidence for the social isolation mechanism. We find that women who are extremely concerned about maintaining social ties are significantly more likely to report higher levels of family stress and domestic violence due to confinement than women who report being not at all concerned about maintaining social ties. Related, COVID-19 could affect domestic violence through emotional cues (e.g., Beland and Brent (2018), and Card and Dahl (2011)). The pandemic outbreak and layoffs can lead to negative emotional shocks and increase the likelihood of domestic violence. ${ }^{10}$ This loss of control might be exacerbated due to isolation and lack of societal protection. ${ }^{11}$

\subsection{Household Bargaining Under Uncertainty Model and Related Theory}

Alternatively, intra-household bargaining model suggests that domestic violence incidents decrease when the relative labour market outcomes (wage or employment) of women increase in the couple. Anderberg et al. (2016)'s model predicts that women's unemployment probability and expected future earnings affect the risk of domestic violence through changes in women's bargaining power relative to their male partner. Many previous papers documented a negative link between women employment and domestic violence against them (Aizer (2010); Bowlus and Seitz (2006); Heise and Kotsadam (2015)). Our data allows us to test empirically the predictions of this simple model using perceived unemployment risks in addition to observed unemployment. Furthermore, our survey data allows us to directly capture perceived financial obligation pressures which signals respondents' future expected earnings. We find that women's perceived financial pressure and thus their perceived inability to meet financial obligations or essential needs due to COVID-19 is positively significantly related to reported family stress and domestic violence. In other words, our findings suggest that women who perceive a major impact of COVID-19 on their ability to meet financial obligations and essential needs are significantly more likely to report higher perceived concerns of family stress and violence in the home than women who perceive no impact.

\footnotetext{
${ }^{10}$ The economic impact on the labour market has been documented in several countries with severe impact on unemployment (e.g. Beland, Brodeur, Mikola and Wright (2020), Beland, Brodeur and Wright (2020), and Lewandowski (2020)).

${ }^{11}$ Another plausible mechanism is increased alcohol and drug consumption. Self-reported data from CPSS sugggest that COVID-19 led to an increase in consumption. More precisely, $14 \%$ and $7 \%$ of men report increased weekly alcohol and cannabis consumption, respectively.
} 
An alternative related mechanism is that a decrease in employment and increase in workfrom-home due to COVID-19 may induce intimate partner violence by increasing the time partners spend together. This is related to the theory of exposure reduction developed by criminologists (Dugan et al. (1999)). Relying on questions related to remote work arrangements from the Canadian Perspective Survey Series (CPSS), we find that remote work does not explain women's perceived concerns about domestic violence. Thus, our results do not provide evidence in support of this channel.

\section{Data and Methodology}

\subsection{Canadian Perspective Survey Series}

We rely on the Canadian Perspective Survey Series to investigate how COVID-19 might affect self-reported perceived risk of domestic violence and family stress. ${ }^{12}$ The CPSS surveyed Canadians between March 29, 2020 and April 3, 2020 using randomly sample households from the Labour Force Survey (LFS) out-going rotation groups between April 2019 and July 2019. The survey sampled 7,242 individuals who had valid email address on file at Statistics Canada, from the 31,896 . The final amount of respondents available in the CPSS dataset is 4,627 individuals. $^{13}$

An important feature of the CPSS is the online collection method which can be done at any point between March 29 and April 3, 2020. This gives respondents flexibility in answering the survey and possibly the privacy needed to answer the questions about concerns they have in their personal life. Data sources which rely on reports of domestic violence from phone calls may under-report the actual number of domestic violence cases during COVID-19 due to the increased time spent with the abuser. With the abuser in close quarters and the opportunities to leave the house decreasing due to isolation, there is no guarantee it will be

\footnotetext{
${ }^{12}$ The CPSS 1 - Impacts of COVID-19 is the first of six surveys being asked approximately every two months as parts of the Canadian Perspectives Survey Series. The second survey does not include questions about domestic violence or family stress.

${ }^{13}$ The CPSS invited valid individuals from the LFS to participate in this online survey through the mail. The mail invitations provided individuals a Secure Access Code and invited them to complete an online SignUp form. Participants could choose not to participate online after filling out "basic demographic information" and providing a valid email address. Attempts were made to follow-up with those who did not access the online Sign-Up which included additional mail, email and telephone.
} 
safe to access help. Although opportunities to respond to an online survey such as the CPSS may also be reduced during COVID-19 times by the same argument, the information can be provided in a more discrete and convenient way than phone calls.

Furthermore, respondents were not aware that they would be asked questions about domestic violence and family stress. The website for the CPSS is particularly vague stating that the "surveys will cover a variety of social topics, such as education, health, and justice. The link to the surveys in this project will be added here as the information becomes available."14

Domestic violence information is taken from answers to the question "How concerned are you about each of the following impacts of COVID-19: Violence in the Home?". Appendix Figure A1 shows that $3 \%$ of respondents in our sample report being "Extremely" concerned about violence in the home. About $5 \%$ of respondents are "Very concerned," $8 \%$ are "Somewhat" concerned and $85 \%$ report not being concerned at all about violence in the home. Among those who are "Very concerned," $62 \%$ are women. In addition, we rely on a question from the CPSS on the impact of COVID-19 on family stress due to confinement. Appendix Figure A1 shows that nearly $30 \%$ of respondents report "Not at all" when asked if they are concerned about the impact of COVID-19 on family stress, nearly $40 \%$ of respondents in our sample report being "Somewhat" concerned, about $20 \%$ are "Very" concerned and just over $10 \%$ report being "Extremely" concerned about family stress.

We empirically test the predictions of the social control theory using this question from the CPSS: "How concerned are you about each of the following impacts of COVID-19: Maintaining social ties?" where respondents are offered four answers ranging from "Not at all" to "Extremely." We also rely on the question "Are you doing any of the following activities for your health? Communication with friends and family" where respondents' choices are "Yes, for my mental health", "Yes, for my physical health", "Yes, for both my mental and physical health" and "No".

We additionally use information about COVID-19's perceived impacts on respondents' ability to meet financial obligations. Possible answers include "Major impact", "Moderate impact", "Minor impact", "No impact" and "Too soon to tell" . We interpret this as proxy for perceived difficulties in expected earnings. If respondents reveal a major impact, we consider

\footnotetext{
${ }^{14}$ See https://www. statcan.gc.ca/eng/survey/household/5311.
} 
this as a signal for a significant perceived income loss, whereas a no impact response signals that individuals did not face any shift in their future earnings. We also use a question that asks respondents who are employed whether they think they might lose their main job or their main self-employment income sources over the next four weeks. The latter question allows us to capture unemployment risk and uncertainty related to future expected earnings. Throughout our analysis, we refer to this as job security. Respondents who are eligible to answer this question include respondents that report being employed, employed and absent because of COVID-19 or employed and absent for reasons not related to COVID-19. About $18 \%(14 \%)$ of respondents "Strongly agree" ("Agree") that they might lose their main job or main self-employment income in the next four weeks. More than $50 \%$ of respondents either "Disagree" or "Strongly disagree."

Appendix Table A1 provides summary statistics. About a quarter of our sample of women who are employed began working from home, which translates to $13 \%$ of the whole sample of women. Over $75 \%$ report being at least "Somewhat" concerned with maintaining social ties, and over $90 \%$ report communication with friends and family as important to either their mental, or, mental and physical health. Approximately 44\% report COVID-19 having at least a "Minor impact" on their ability to meet financial obligations or essential needs and between 6 and $8 \%$ of females received relief for financial obligations.

\subsection{Model}

The dependent variables are answers to the family stress and domestic violence questions. Specifically, we estimate:

$$
\begin{aligned}
Y_{i}=\alpha+\beta \text { EmploymentStatus }_{i}+\theta \text { WorkArrangement }_{i}+\phi \text { JobSecurity }_{i} & \\
& + \text { SFinancialPressure }_{i}+X_{i}^{\prime} \gamma+\varepsilon_{i}
\end{aligned}
$$

where $Y_{i}$ is woman $i$ 's perceived concern about family stress/violence in the home following COVID-19. Employment Status ${ }_{i}$ are dummy variables capturing individual $i$ 's employment status: employed, employed and absent due to COVID, employed and absent not due to COVID or not employed. Work Arrangement $i$ are dummy variables indicating whether 
individual $i$ 's work location has changed from outside the home to at home, or it remains at home, or whether individual $i$ 's work location remains outside the home and finally whether

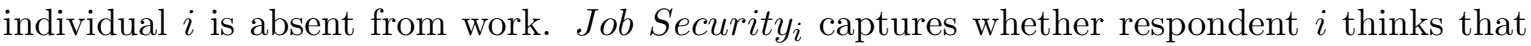
they might lose their main job or their main self-employment income sources over the next four weeks. Financial Pressure P $_{i}$ capturing COVID-19 perceived impact on individual $i$ 's ability to meet financial obligations or essential needs. This varies from "Major impact" to "No impact."

$X_{i}^{\prime}$ is a set of demographic controls at the individual-level including age group dummies, marital status of respondent, dummies for having a child under 18 on the reference week residing in the dwelling, and highest level of education ever completed.

We construct an alternative specification that is similar to equation 1, but omitting dummy variables for Job Security $i$ and Financial Pressure P $_{i}$, but instead our model includes dummy variables for answers to the questions on concerns about maintaining social ties and communication with friends and family for mental health and physical health.

We rely on a question from the CPSS that asks respondents whether they received relief for financial obligations. These include relief for rent or mortgage payments, car payments, or other household bills. Such payments, especially home mortgages, signal financial stability and thus risks of financial pressures to meet these obligations increase foreclosure risks, stress and potentially induces risks for domestic violence (Lersch et al. (2014); Pattavina et al. (2015)). We thus check whether there exists a heterogeneous effect of financial pressure on family stress and domestic violence, depending on whether individuals received financial relief. We construct a final specification that is based on equation 1 but that includes individual $i$ 's work arrangement, individual $i$ 's financial pressure and dummies for Financial Relief $f_{i}$ which indicates whether individual $i$ received/did not receive such relief, or whether it was not required.

\section{$5 \quad$ Findings}

In this section, we present the results on the relationship between individuals' perceived impacts of COVID-19, family stress and domestic violence. 
We present estimates of equation 1 in Tables 1 and 2. We first test whether employment status, work arrangements (work location), job security (worries about losing one's job) and financial pressure (self-reported ability to meet financial obligations) are related to family stress (Table 1) and domestic violence (Table 2). In column 1, we find that females who are not employed, employed but absent from work due to COVID-19 and employed but absent for other reasons were not significantly more likely to report higher levels of family stress due to confinement or domestic violence than women who are employed.

As women work increasingly from home because of social distancing, they may be losing access to support from co-workers and spend more time with their partner. We test these mechanisms in column 2. We find no evidence that females who are now working from home because of COVID-19 report different levels of family stress and domestic violence than women working outside of home and those already working from home prior to the pandemic. Working from home might not affect concerns for family stress and domestic violence as it allows keeping some social ties. Appendix Table A2 shows support for this hypothesis. It shows that women who move to working from home because of COVID-19 are not more likely than women who still work outside the home to have heightened concerns for losing social ties. ${ }^{15}$

So far, our findings suggest that employment status and work arrangements are not related to women's perceived impacts of COVID-19 on family stress and domestic violence. This is against the prior that increased reported domestic violence might be related to work-at-home conditions and employment status linked to lockdowns and isolation.

To understand the mechanisms through which COVID-19 might impact concerns about family stress and domestic violence, we examine in column 3 whether job security matters. Our findings suggest that women who strongly agree that they will lose their main job or main self-employment income in the next four weeks report higher levels of family stress in comparison to those who strongly disagree. However, we find no evidence in support of higher reported concerns about violence in the home.

In column 4, we include dummies in our model for the answers to the ability to meet

\footnotetext{
${ }^{15}$ The Table shows that those who are absent from work are however more likely to report increased concerns in maintaining social ties.
} 
financial obligations question. We find that women answering "Major impact" to the question regarding their perceived COVID-19 impacts on their ability to meet financial obligations and essential needs are significantly more likely to report higher levels of family stress and violence in the home than those answering "No impact."

One way to gauge the magnitude of our estimates is to standardize the dependent variable for all respondents to have a mean of zero and a standard deviation of one. We then run OLS regressions using equation 1. See Appendix Tables A3 and A4. Our estimates suggest that women who perceive a major impact of COVID-19 on the ability to meet their financial obligations or essential needs are 52 and 29 percent of a standard deviation more likely to report higher levels of family stress due to confinement and domestic violence respectively than women who report no impact on their ability to meet financial obligations because of COVID-19. While women who report minor impact, are just 4 percent of standard deviation more likely to report higher concern regarding violence in the home. The inclusion of our work arrangements dummies (columns 5 and 6) has no effect on the magnitude or significance of our financial pressure estimates.

To investigate the social isolation mechanism, we rely on questions from the CPSS that asks respondents about their perceived impact of COVID-19 on their ability to maintain social ties and whether they are communicating with their friends and family for their mental and/or physical health. Our estimates show that an increase in women's concern about maintaining social ties is positively associated with their concerns regarding domestic violence and family stress from confinement. Results using ordered probit estimation are reported in Tables 3 and 4.

Conditional on work arrangement dummies, and controlling for individual level demographic controls, we find that women who report being extremely concerned about maintaining social ties as a result of COVID-19 are 120 and 75 percent of a standard deviation more likely to report higher levels of family stress and domestic violence respectively than women who report not being concerned at all about maintaining social ties. Women who are very or somewhat concerned are about 70 and about 35 percent more likely to report higher concern about family stress in comparison to women reporting not being concerned at all. Regarding violence in the home, women who are very or somewhat concerned about 
maintaining social ties are about 35 and about 20 percent more likely to report higher concern about domestic violence in comparison to those who report not being concerned at all. ${ }^{16}$ We do not find evidence in support of a link between communicating with friends and family for women's mental and/or physical health and their reported perceived family stress and domestic violence. ${ }^{17}$

Next, we investigate whether receiving financial relief mitigates the economic impacts of COVID-19 on concerns about family stress and domestic violence. We rely on a question from CPSS that asks respondents whether they received financial relief for financial obligations which cover rent (or mortgage) payments, car payments or other household bills.

The dependent variable in columns $1-3$ of Table 5 is our family stress variable. Column 1 shows that women who receive financial relief for financial obligations are more likely to report higher family stress in comparison to those who do not receive financial relief. This is likely since women receiving such financial transfers are likely facing financial difficulties. This is especially true given that over $90 \%$ of women report "Not required" or "No" to the question regarding whether or not they received financial relief. Column 2 shows that the positive significant correlation between financial relief and reported perceived family stress remains robust to the inclusion of work arrangements. In column 3, we simultaneously include in the model dummies for work arrangements, financial obligation and financial relief in our model. Our results show that our financial worries estimates remain positively related to perceived concerns about family stress. In other words, receiving financial relief does not mitigate the impact of financial worries on family stress.

In columns 4 to 6 of Table 5, we change our dependent variable of interest, and now investigate the determinants of women's perceived concern about violence in the home. Using the same structure as in columns 1 to 3 , we find that a positive association between reporting receiving financial relief and domestic violence, but the standard errors are large and our estimate is statistically insignificant at conventional levels. We find no evidence that receiving financial relief mitigates the estimated effect of financial worries on reported domestic violence

\footnotetext{
${ }^{16}$ Results using OLS regressions with standardized dependent variables are reported in Appendix Tables A5, A6 and A7.

${ }^{17}$ Tables A8 and A9 present results for family stress and domestic violence by demographic individual-level controls, respectively.
} 
levels.

To summarize, our results provide suggestive evidence that financial transfers are not successful in partly alleviating the effect of women's perceived financial stress on family stress and domestic violence.

\section{Conclusion}

In this paper, we aim to disentangle the mechanisms through which COVID-19 may affect family stress and domestic violence. We rely on a unique survey, the Canadian Perspective Survey, which includes questions on the effect of COVID-19 and confinement on familly stress, domestic violence, concerns about financial obligations, remote work as well as demographic variables.

Our results suggest that work arrangements such as remote work are not increasing women's perceived impacts of COVID-19 on familly stress and domestic violence. These results are important given the large and widespread increase in remote work and the potential for long lasting increase in work from home arrangements (e.g. Sachedina and Cousins $(2020))$.

Rather, our results suggest that women's concerns regarding inability to meet financial obligations due to COVID-19 leads to a significant increase in reported familly stress and domestic violence. Our findings are consistent with intra-household bargaining model in which expected future earnings affect the risk of domestic violence for women. In addition to documenting higher perceived risks of domestic violence for women with high levels of financial worries, we can offer a new perspective on the impact of social isolation on family violence. Using questions on the impact of COVID-19 on women's ability to maintain social ties, we find that an increase in women's concern about maintaining social ties is positively associated with concerns regarding domestic violence and familly stress from confinement. These results are consistent with prior research highliting the key role of societal controls and protection that can increase the costs of perpetrating domestic violence and reduce incidence of familly violence (e.g., Gelles (1983)).

In addition, we investigate whether receiving financial relief mitigates the effect of women's 
perceived impact of COVID-19 on their ability to meet financial obligations on perceived concerns about family stress and domestic violence. Our results appear to suggest that receiving financial relief are not successful in alleviating the effect of women's perceived financial stress on domestic violence. The Canadian government has pledged up to $\$ 50$ million (CAD) in their COVID-19 Economic Response Plan towards women's shelters and sexual assault centres, with $\$ 40$ million being given out by May 16, 2020.18 Our analysis suggest that this is a step in the right direction to help mitigate the negative effect of COVID-19 on familly stress and violence.

\section{References}

Aizer, A.: 2010, The gender wage gap and domestic violence, American Economic Review 100(4), 1847-1859.

Alesina, A., Brioschi, B. and La Ferrara, E.: Forthcoming, Violence against women: A crosscultural analysis for Africa, Economica.

Ali, U., Herbst, C. M. and Makridis, C. A.: 2020, The impact of COVID-19 on the US child care market: Evidence from stay-at-home orders. IZA Discussion Paper 13261.

Alon, T., Doepke, M., Olmstead-Rumsey, J. and Tertilt, M.: 2020, The impact of COVID-19 on gender equality. NBER Working Paper 26947.

Anastario, M., Shehab, N. and Lawry, L.: 2009, Increased gender-based violence among women internally displaced in mississippi 2 years post-hurricane katrina, Disaster Medicine and Public Health Preparedness 3(1), 18-26.

Anderberg, D., Rainer, H., Wadsworth, J. and Wilson, T.: 2016, Unemployment and domestic violence: Theory and evidence, Economic Journal 126(597), 1947-1979.

Armbruster, S. and Klotzbucher, V.: 2020, Lost in lockdown? Covid-19, social distancing, and mental health in Germany. CEPR COVID Economics.

Beland, L.-P. and Brent, D. A.: 2018, Traffic and crime, Journal of Public Economics 160, 96116.

Beland, L.-P., Brodeur, A., Mikola, D. and Wright, T.: 2020, The Short-Term Economic Consequences of COVID-19: Occupation Tasks and Mental Health in Canada. IZA Discussion Paper 13254.

Beland, L.-P., Brodeur, A. and Wright, T.: 2020, COVID-19, stay-at-home orders and employment: Evidence from CPS data. IZA Discussion Paper 13282.

Boserup, B., McKenney, M. and Elkbuli, A.: 2020, Alarming trends in us domestic violence during the covid-19 pandemic, American Journal of Emergency Medicine.

\footnotetext{
${ }^{18}$ See https://cfc-swc.gc.ca/fun-fin/shelters-refuges-en.html for additional details.
} 
Bowlus, A. J. and Seitz, S.: 2006, Domestic violence, employment, and divorce, International Economic Review 47(4), 1113-1149.

Brodeur, A., Clark, A. E., Flèche, S. and Powdthavee, N.: 2020, COVID-19, Lockdowns and Well-Being: Evidence from Google Trends. IZA Discussion Paper 13204.

Browne, A.: 1987, When battered women kill, New York: The Free Press.

Card, D. and Dahl, G. B.: 2011, Family violence and football: The effect of unexpected emotional cues on violent behavior, Quarterly Journal of Economics 126(1), 103-143.

Carlen, P.: 1983, Women's imprisonment, Boston: Routeledge and K. Paul.

Cazenave, N. and Straus, M.: 1979, Race, class, network embeddedness and family violence, Journal of Comparative Family Studies 10(3), 281-300.

Dugan, L., Nagin, D. S. and Rosenfeld, R.: 1999, Explaining the decline in intimate partner homicide: The effects of changing domesticity, women's status, and domestic violence resources, Homicide Studies 3(3), 187-214.

Eaton, M.: 1986, Justice for women, Milton Keynes, PA: Open University Press.

Enarson, E.: 1999, Violence against women in disasters: A study of domestic violence programs in the United States and Canada, Violence Against Women 5(7), 742-768.

Farmer, A. and Tiefenthaler, J.: 1997, An economic analysis of domestic violence, Review of Social Economy 55(3), 337-358.

Gelles, R.: 1993, Through a sociological lens: Social structure and family violence, in R. J. Gelles and D. R. Loseke (eds), Current Controversies on Family Violence, Newbury Park, CA: Sage, pp. 31-46.

Gelles, R. J.: 1983, An exchange/Social control theory, The Dark Side of Families: Current Family Violence Research pp. 151-165.

Gelles, R. J. and Straus, M.: 1979, Determinants of violence in the family: Toward a theoretical integration, Contemporary Theories about the Family, New York, NY: Free Press.

Gupta, S., Montenovo, L., Nguyen, T. D., Rojas, F. L. et al.: 2020, Effects of social distancing policy on labor market outcomes. NBER Working Paper 27280.

Hamermesh, D. S.: 2020, Lockdowns, loneliness and life satisfaction. IZA Discussion Paper 13140.

Heise, L. and Kotsadam, A.: 2015, Cross-national and multilevel correlates of partner violence: An analysis of data from population-based surveys, The Lancet Global Health 3(6), 332-340.

Iyengar, R.: 2009, Does the certainty of arrest reduce domestic violence? Evidence from mandatory and recommended arrest laws, Journal of Public Economics 93(1), 85-98.

Lersch, K., Sellers, C. and Cromwell, P.: 2014, Residential foreclosure rates and calls for service for domestic disputes: An explanatory analysis, American Journal of Criminal Justice 40(3), 579-592. 
Leslie, E. and Wilson, R.: 2020, Sheltering in place and domestic violence: Evidence from calls for service during COVID-19. Available at SSRN.

Lewandowski, P.: 2020, Occupational exposure to contagion and the spread of covid-19 in Europe. IZA Discussion Paper 13227.

Nye, I.: 1958, Family relationships and delinquent behavior, New York: John Wiley and Sons.

Parkinson, D. and Zara, C.: 2013, The hidden disaster: Domestic violence in the aftermath of natural disaster, Australian Journal of Emergency Management 28(2), 28.

Patel, R.: 2020, Minister says COVID-19 is empowering domestic violence abusers as rates rise in parts of Canada, $C B C$.

Pattavina, A., Socia, K. M. and Zuber, M. J.: 2015, Economic stress and domestic violence: Examining the impact of mortgage foreclosures on incidents reported to the police, Justice Research and Policy 16(2), 147-164.

Payne, J., Morgan, A. and Piquero, A. R.: 2020, Covid-19 and social distancing measures in queensland australia are associated with short-term decreases in recorded violent crime. SocArXiv.

Sachedina, O. and Cousins, B.: 2020, Will the COVID-19 pandemic lead to a permanent revolution in working from home? CTV News.

Schwandt, H.: 2020, Pregnancy during the pandemic. IZA Policy Paper 161.

Sevilla, A. and Smith, S.: 2020, Baby steps: The gender division of childcare during the COVID-19 pandemic. IZA Discussion Paper13302.

Shana Conroy, M. B. and Savage, L.: 2019, Family violence in Canada: A statistical profile, 2018, Juristat (Statistics Canada Catalogue no. 85-002-X. Ottawa, ON: Statistics Canada). URL: https://www150.statcan.gc.ca/n1/pub/85-002-x/2019001/article/00018-eng.pdf

Stets, J. E. and Straus, M. A.: 1990, The marriage license as hitting license: A comparison of assaults in dating, cohabiting, and married couples, in M. A. Straus and R. J. Gelles (eds), Physical Violence in American Families: Risk Factors and Adaptations to Violence in 8,145 Families, New Brunswick, NJ: Transaction, pp. 227-244.

Tubadji, A., Boy, F. and Webber, D. J.: 2020, Narrative economics, public policy and mental health. CEPR COVID Economics.

Usher, K., Bhullar, N., Durkin, J., Gyamfi, N. and Jackson, D.: 2020, Family violence and COVID-19: Increased vulnerability and reduced options for support, International Journal of Mental Health Nursing .

Walker, L.: 1989, Terrifying love, New York: Harper and Row Publishers.

Wells, L. and Rankin, J.: 1988, Direct parental controls and delinquency, Criminology 26(2), 263-285. 
Table 1: Concerns about Family Stress: Employment, Work Arrangements and Financial Worries

(1)

$(2)$

(3)

(4)

(5)

(6)

\section{Employment status}

Employed, Absent, not COVID

0.289

$(0.1955)$

Employed, absent due to COVID $\quad 0.0995$

$(0.1123)$

$$
\text { Not Employed } \quad 0.0906
$$

\section{Work from home}

Work location changed to home

0.00608

$0.0379 \quad-0.00908$

$(0.1131)$

$(0.1093) \quad(0.1145)$

Work location remains at home

$-0.0411$

$-0.102$

$-0.117$

$(0.1426)$

(0.1424)

Absent from work

0.141

(0.1422)

$\begin{array}{lr}0.131 & -0.000877 \\ (0.1203) & (0.1273)\end{array}$

(0.1213)

Might lose job

Strongly agree

Agree

Neither agree nor disagree

Disagree

Ability to meet financial obligations
0.264

(0.1358)

0.215

(0.1441)

0.300

(0.1411)

0.146

(0.1221)
0.230

(0.1354)

0.209

(0.1446)

0.308

(0.1406)

0.165

(0.1227)
Major impact
Moderate impact
Minor impact
Too soon to tell

Major impact
Moderate impact
Minor impact
Too soon to tell

Major impact
Moderate impact
Minor impact
Too soon to tell

Major impact
Moderate impact
Minor impact
Too soon to tell

Observations

Individual Controls
2433

$\checkmark$

\begin{tabular}{ccc}
0.555 & & 0.564 \\
$(0.1206)$ & & $(0.1253)$ \\
0.452 & & 0.453 \\
$(0.1088)$ & & $(0.1110)$ \\
0.234 & & 0.239 \\
$(0.1099)$ & & $(0.1112)$ \\
0.300 & & 0.303 \\
$(0.0954)$ & & $(0.0967)$ \\
& & \\
2433 & 1448 & 2433 \\
$\checkmark$ & $\checkmark$ & $\checkmark$ \\
\hline
\end{tabular}

Notes: Authors' calculations. Data from the CPSS. All regressions are estimated using an ordered probit with robust standard errors and weights applied. All observations are female. The dependent variable asks individuals their concern about the impact of COVID-19 on family stress due to confinement. The dependent variable takes on the values 1 (Not at all), 2 (Somewhat), 3 (Very), 4 (Extremely). All columns include dummies for age, marital status, whether the dwelling has a child under the age of 18 residing in it, and highest education level attained by the respondent. Each independent variable of interest also contains a "Not stated" category which was controlled for (not shown). Column 1 appends the controls with a categorical variable describing the employment status of the respondent. The base category is "Employed". Column 2 appends the controls with a categorical variable describing if the location of where the respondent worked has changed. The base category is "Work location remains outside the home". Column 3 appends the controls with a categorical variable describing if respondents feel they will lose their main job or main self-employment income in the next 4 weeks. The base category is "Strongly disagree". Observations are fewer because we omit those who are not valid. Column 4 appends the controls with a categorical variable describing if COVID-19 impacted the respondent's ability to meet financial obligations or essential needs. The base category is "No impact". 
Table 2: Concerns about Violence in the Home: Employment, Work Arrangements and Financial Worries

(1)

$(2)$

(3)

(4)

(5)

(6)

\section{Employment status}

Employed, Absent, not COVID $\quad-0.148$

(0.1936)

Employed, absent due to COVID $\quad 0.0706$

(0.1704)

Not Employed $\quad-0.0410$

$(0.1123)$

\section{Work from home}

Work location changed to home

Work location remains at home

Absent from work

Might lose job

Strongly agree

Agree

Neither agree nor disagree

Disagree

\section{Ability to meet financial obligations}

Major impact

Moderate impact

Minor impact

Too soon to tell
$-0.0570$

$(0.1481)$

$-0.0349$

(0.1976)

0.0105

(0.1642)
$-0.0434$

(0.1468)

$-0.0365$

(0.1907)

0.0359

(0.1699)
$-0.0518$

(0.1515)

$-0.0818$

(0.2012)

$-0.0813$

(0.1605)
$-0.208$

(0.1598)

0.0569

(0.1677)

$-0.00166$

(0.2180)

$-0.218$

(0.1577)

Observations

Notes: Authors' calculations. Data from the CPSS. All regressions are estimated using an ordered probit with robust standard errors and weights applied. All observations are female. The dependent variable asks individuals their concern about the impact of COVID-19 on violence in the home. The dependent variable takes on the values 1 (Not at all), 2 (Somewhat), 3 (Very), 4 (Extremely). All columns include dummies for age, marital status, whether the dwelling has a child under the age of 18 residing in it, and highest education level attained by the respondent. Each independent variable of interest also contains a "Not stated" category which was controlled for (not shown). Column 1 appends the controls with a categorical variable describing the employment status of the respondent. The base category is "Employed". Column 2 appends the controls with a categorical variable describing if the location of where the respondent worked has changed. The base category is "Work location remains outside the home". Column 3 appends the controls with a categorical variable describing if respondents feel they will lose their main job or main self-employment income in the next 4 weeks. The base category is "Strongly disagree". Observations are fewer because we omit those who are not valid. Column 4 appends the controls with a categorical variable describing if COVID-19 impacted the respondent's ability to meet financial obligations or essential needs. The base category is "No impact". 
Table 3: Concerns about Family Stress: Social Isolation

(1)

$(2)$

(3)

(4)

(5)

(6)

\section{Employment status}

Employed, Absent, not COVID $\quad 0.289$

Employed, absent due to COVID $\quad 0.0995$

$(0.1123)$

Not Employed $\quad 0.0906$

$(0.0846)$

Work from home

Work location changed to home

Work location remains at home

Absent from work
0.00608

(0.1131)

$-0.0411$

$(0.1426)$

0.141

(0.1213)
$0.00164 \quad 0.00300$

(0.1190) (0.1138)

$-0.0622-0.0412$

$(0.1483) \quad(0.1434)$

$0.0284 \quad 0.139$

$(0.1289) \quad(0.1213)$

\section{Concerned with maintaining social ties}

$$
\begin{array}{r}
\text { Somewhat } \\
\text { Very } \\
\text { Extremely }
\end{array}
$$

\section{Communicating with friends and family}

$$
\begin{gathered}
0.437 \\
(0.0937) \\
0.822 \\
(0.1111) \\
1.396 \\
(0.1801)
\end{gathered}
$$

\begin{tabular}{|c|c|c|c|c|c|}
\hline & & & $\begin{array}{c}-0.155 \\
(0.6311)\end{array}$ & & $\begin{array}{c}-0.181 \\
(0.6372)\end{array}$ \\
\hline & & & $\begin{array}{c}0.0397 \\
(0.0748)\end{array}$ & & $\begin{array}{c}0.0381 \\
(0.0755)\end{array}$ \\
\hline & & & $\begin{array}{c}-0.115 \\
(0.1550)\end{array}$ & & $\begin{array}{c}-0.120 \\
(0.1545)\end{array}$ \\
\hline 2433 & 2433 & 2433 & 2433 & 2433 & 2433 \\
\hline$\checkmark$ & $\checkmark$ & $\checkmark$ & $\checkmark$ & $\checkmark$ & $\checkmark$ \\
\hline
\end{tabular}

0.822
Yes, for my physical health
Yes, for my mental and physical health
No

Yes, for my physical health
Yes, for my mental and physical health
No

No
Observations

Individual Controls

Notes: Authors' calculations. Data from the CPSS. All regressions are estimated using an ordered probit with robust standard errors and weights applied. All observations are female. The dependent variable asks individuals their concern about the impact of COVID-19 on family stress due to confinement. The dependent variable takes on the values 1 (Not at all), 2 (Somewhat), 3 (Very), 4 (Extremely). All columns include dummies for age, marital status, whether the dwelling has a child under the age of 18 residing in it, and highest education level attained by the respondent. Each independent variable of interest also contains a "Not stated" category which was controlled for (not shown). Column 1 appends the controls with a categorical variable describing the employment status of the respondent. The base category is "Employed". Column 2 appends the controls with a categorical variable describing if the location of where the respondent worked has changed. The base category is "Work location remains outside the home". Column 3 appends the controls with a categorical variable describing how concerned the respondents are for maintaining social ties following the impacts of COVID-19. The base category is "Not at all". Column 4 appends the controls with a categorical variable describing if respondents are communicating with friends and family for their health. The base category is "Yes, for my mental health" 
Table 4: Concerns about Violence in the Home: Social isolation

(1)

(2)

(3)

(4)

(5)

(6)

\section{Employment status}

Employed, Absent, not COVID $\quad-0.148$

Employed, absent due to COVID $\quad 0.0706$

(0.1704)

Not Employed $\quad-0.0410$

$(0.1123)$

Work from home

Work location changed to home

Work location remains at home

Absent from work
$-0.0570$

(0.1481)

$-0.0349$

(0.1976)

0.0105

(0.1642)
$-0.0830 \quad-0.0473$

$(0.1457) \quad(0.1495)$

$-0.0390-0.0322$

$(0.2041) \quad(0.1983)$

$-0.0634 \quad 0.0168$

$(0.1743) \quad(0.1637)$

\section{Concerned with maintaining social ties}

$$
\begin{array}{r}
\text { Somewhat } \\
\text { Very } \\
\text { Extremely }
\end{array}
$$

\section{Communicating with friends and family}

Yes, for my physical health

Yes, for my mental and physical health
0.381

(0.1292)

0.518

(0.1358)

0.883

(0.1884)
0.381

(0.1287)

0.520

(0.1360)

0.889

(0.1899)

\begin{tabular}{ccc}
0.252 & & 0.247 \\
$(0.4579)$ & & $(0.4644)$ \\
-0.00400 & & -0.00560 \\
$(0.1020)$ & & $(0.1025)$ \\
0.203 & & 0.204 \\
$(0.1827)$ & & $(0.1830)$ \\
& & \\
2429 & 2429 & 2429 \\
$\checkmark$ & $\checkmark$ & $\checkmark$ \\
\hline
\end{tabular}

Observations

$2429 \quad 2429$

2429

$\checkmark$

Notes: Authors' calculations. Data from the CPSS. All regressions are estimated using an ordered probit with robust standard errors and weights applied. All observations are female. The dependent variable asks individuals their concern about the impact of COVID-19 on violence in the home. The dependent variable takes on the values 1 (Not at all), 2 (Somewhat), 3 (Very), 4 (Extremely). All columns include dummies for age, marital status, whether the dwelling has a child under the age of 18 residing in it, and highest education level attained by the respondent. Each independent variable of interest also contains a "Not stated" category which was controlled for (not shown). Column 1 appends the controls with a categorical variable describing the employment status of the respondent. The base category is "Employed". Column 2 appends the controls with a categorical variable describing if the location of where the respondent worked has changed. The base category is "Work location remains outside the home". Column 3 appends the controls with a categorical variable describing how concerned the respondents are for maintaining social ties following the impacts of COVID-19. The base category is "Not at all". Column 4 appends the controls with a categorical variable describing if respondents are communicating with friends and family for their health. The base category is "Yes, for my mental health" 
Table 5: Concerns about Family Stress and Violence in the Home: Receiving Financial Relief

(1)

$(2)$

(3)

(4)

(5)

(6)

\section{Receiving financial relief}

$\begin{array}{ccccccc}\text { Yes } & 0.332 & 0.320 & 0.254 & 0.205 & 0.202 & 0.147 \\ & (0.1715) & (0.1709) & (0.1747) & (0.1844) & (0.1859) & (0.1857) \\ \text { Not required } & -0.0384 & -0.0372 & 0.110 & 0.0834 & 0.0878 & 0.186 \\ & (0.0723) & (0.0742) & (0.0770) & (0.0944) & (0.0948) & (0.1007)\end{array}$

\section{Work from home}

Work location changed to home

Work location remains at home

Absent from work

\section{Ability to meet financial obligations}

Major impact

Moderate impact

Minor impact

Too soon to tell

Observations

Individual Controls

$\begin{array}{cccc}0.0180 & -0.00903 & -0.0582 & -0.0605 \\ (0.1126) & (0.1136) & (0.1470) & (0.1494) \\ -0.0332 & -0.108 & -0.0265 & -0.0863 \\ (0.1444) & (0.1425) & (0.1966) & (0.1976) \\ 0.122 & -0.00378 & 0.0150 & -0.0783 \\ (0.1233) & (0.1267) & (0.1655) & (0.1611)\end{array}$

$\begin{array}{cc}0.122 & -0.00378 \\ (0.1233) & (0.1267)\end{array}$

$(0.1655)$

$(0.1611)$
0.428

$(0.1744)$

(0.1338)

(0.1177)

(0.1101)

0.0891

$(0.0955)$

Notes: Authors' calculations. Data from the CPSS. All regressions are estimated using an ordered probit with robust standard errors and weights applied. All observations are female. The dependent variable in columns 1 to 3 asks individuals their concern about the impact of COVID-19 on family stress due to confinement. The dependent variable takes on the values 1 (Not at all), 2 (Somewhat), 3 (Very), 4 (Extremely). The dependent variable in columns 4 to 6 asks individuals their concern about the impact of COVID-19 on violence in the home. The dependent variable takes on the values 1 (Not at all), 2 (Somewhat), 3 (Very), 4 (Extremely). Those who were assigned to the "Not stated" category in the dependent variable were omitted. All columns include dummies for age, marital status, whether the dwelling has a child under the age of 18 residing in it, and highest education level attained by the respondent. Each independent variable of interest also contains a "Not stated" category which was controlled for (not shown). Column 1 appends the controls with a categorical variable describing if respondents received financial relief for financial obligations. The base category is "No". Column 2 appends the controls with a categorical variable describing if respondents received financial relief for financial obligations. The base category is "No" and with a categorical variable describing if the location of where the respondent worked has changed. The base category is "Work location remains outside the home". Column 3 appends the controls with a categorical variable describing if respondents received financial relief for financial obligations. The base category is "No"; a categorical variable describing if the location of where the respondent worked has changed. The base category is "Work location remains outside the home" and categorical variable describing if COVID-19 impacted the respondent's ability to meet financial obligations or essential needs. The base category is "No impact". Columns 4 to 6 repeat the same specifications of columns 1 to 3 but the dependent variable is now women's concern about the impact of COVID-19 on violence in the home. 


\section{Appendix}

Figure A1: Concerns about violence in the home and family stress due to confinement (only women).
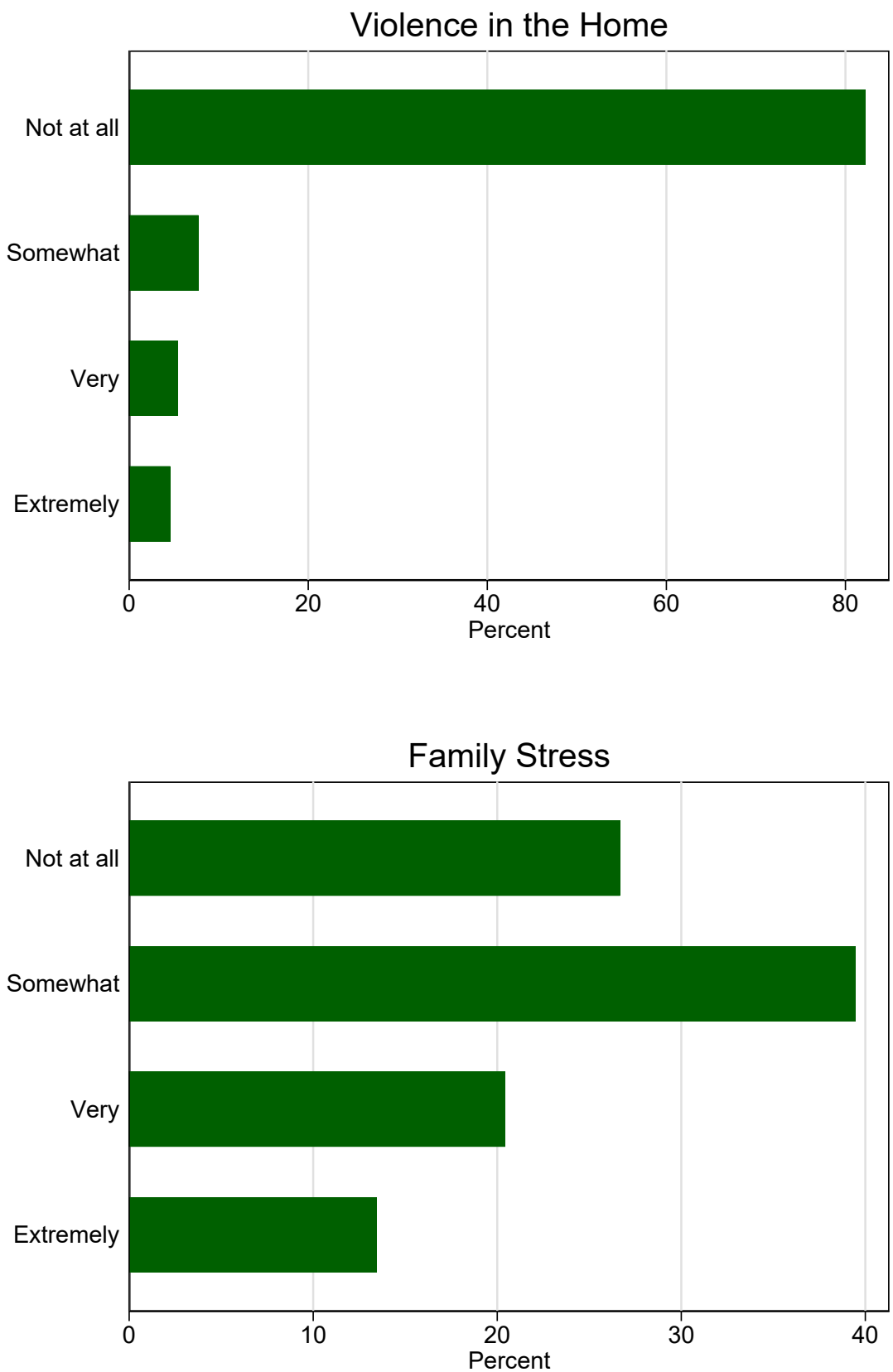

Notes: Authors' calculations. Data from the Canadian Perspectives Survey Series 1 with final weights applied to all subgraphs. We restrict the sample to women. 
Table A1: Summary Statistics for Dependent and Independent Variables

\begin{tabular}{|c|c|c|c|c|c|}
\hline \multicolumn{6}{|l|}{ Dependent Variables } \\
\hline & Mean & Std. Dev. & Max & Min & Count \\
\hline Family stress from confinement & 2.12 & 0.96 & 4.00 & 1.00 & 2433 \\
\hline Violence in the home & 1.29 & 0.74 & 4.00 & 1.00 & 2429 \\
\hline
\end{tabular}

Independent Variables

All Females (\%) $\quad$ Employed Females (\%)

Employment status

$\begin{array}{lll}\text { Employed } & 37.5 & 70.4\end{array}$

$\begin{array}{lll}\text { Employed, absent, not COVID } & 4.1 & 7.7\end{array}$

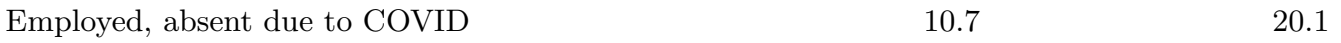

$\begin{array}{lll}\text { Not Employed } & 45.9 & 0.0\end{array}$

Not Stated $\quad 1.7 \quad 1.7$

Telework Status

$\begin{array}{lll}\text { Work location changed to home } & 13.2 & 24.8\end{array}$

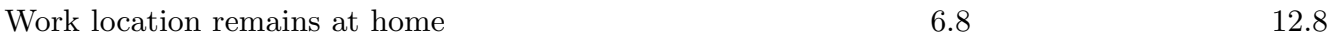

$\begin{array}{lll}\text { Work remains outside home } & 16.2 & 30.4\end{array}$

$\begin{array}{lll}\text { Absent from work } & 14.9 & 27.9\end{array}$

$\begin{array}{lll}\text { Not Stated } & 48.9 & 4.1\end{array}$

Concerned with maintaining social ties

$\begin{array}{lll}\text { Not at all } & 22.0 & 22.3\end{array}$

$\begin{array}{lll}\text { Somewhat } & 42.5 & 42.5\end{array}$

$\begin{array}{lll}\text { Very } & 23.9 & 22.9\end{array}$

Extremely $\quad 11.2 \quad 12.1$

$\begin{array}{lll}\text { Not stated } & 0.4 & 0.2\end{array}$

Communicating with friends and family

$\begin{array}{lll}\text { Yes, for my mental health } & 53.2 & 59.0\end{array}$

Yes, for my physical health $\quad 0.5 \quad 0.4$

Yes, for my mental and physical health $\quad 40.5 \quad 35.3$

No $\quad 5.5 \quad 5.1$

$\begin{array}{lll}\text { Not stated } & 0.3 & 0.1\end{array}$

COVID-19 impacts ability meet financial obligations

$\begin{array}{lll}\text { Major impact } & 12.6 & 16.2\end{array}$

Moderate impact $\quad 15.4 \quad 16.3$

Minor impact $\quad 16.2 \quad 15.5$

$\begin{array}{lll}\text { No impact } & 31.9 & 28.5\end{array}$

$\begin{array}{lll}\text { Too soon to tell } & 23.7 & 23.4\end{array}$

$\begin{array}{lll}\text { Not stated } & 0.2 & 0.0\end{array}$

\begin{tabular}{lcc} 
Received relief for financial obligations & & \\
Yes & 6.6 & 61.4 \\
No & 55.8 & 30.2 \\
Not required & 37.0 & 0.1 \\
Not stated & 0.6 & 1448 \\
\hline bservations & 2433 & \\
\hline
\end{tabular}

Notes: Authors' calculations. All observations are female and are weighted. Both columns correspond to the sample associated with the family stress outcomes. "All Females" is our whole sample of females used in our regressions while "Employed Females" is only the subset of those females employed. 
Table A2: Concerns about Maintaining Social Ties: Employment, Work Arrangements and Communication with Friends and Family

(1)

(2)

(3)

(4)

\section{Work from home}

Work location changed to home

0.0144

0.0344

$(0.1218)$

$(0.1232)$

Work location remains at home

0.0650

0.0786

$(0.1300)$

$(0.1333)$

Absent from work

0.306

(0.1181)

\section{Employment status}

Employed, Absent, not COVID

0.456

0.430

(0.1618)

(0.1587)

Employed, absent due to COVID

0.231

0.239

(0.1182)

$(0.1180)$

Not Employed

0.0697

0.0628

(0.0865)

(0.0876)

\section{Communicating with friends and family}

Yes, for my physical health

0.132

0.100

(0.4164)

(0.4213)

Yes, for my mental and physical health

0.269

(0.0814)

0.265

$-0.106$

No

(0.1329)

$-0.100$

(0.1318)

\begin{tabular}{lcccc} 
Observations & 2430 & 2430 & 2430 & 2430 \\
Individual Controls & $\checkmark$ & $\checkmark$ & $\checkmark$ & $\checkmark$ \\
\hline \hline
\end{tabular}

Notes: Authors' calculations. Data from the CPSS. All columns are estimated using an ordered probit with robust standard errors and weights applied. All observations are female. The dependent variable in columns 1 to 3 asks individuals their concern about the impact of COVID-19 on concerns for maintaining social ties. The dependent variable takes on the values 1 (Not at all), 2 (Somewhat), 3 (Very), 4 (Extremely). We omit observations who did not state responses. All columns include dummies for age, marital status, whether the dwelling has a child under the age of 18 residing in it, and highest education level attained by the respondent. Each independent variable of interest also contains a "Not stated" category which was controlled for (not shown). Column 1 appends the controls with a categorical variable describing if the location of where the respondent worked has changed. The base category is "Work location remains outside the home". Column 2 appends the controls with a categorical variable describing the employment status of the respondent. The base category is "Employed". Column 3 appends the specification of column (1) with a categorical variable describing if respondents are communicating with friends and family for their health. The base category is "Yes, for my mental health" Column 4 appends the specification of column (2) with a categorical variable describing if respondents are communicating with friends and family for their health. The base category is "Yes, for my mental health" 
Table A3: Standardized Dependent Variable: Concerns about Family Stress: Employment, Work Arrangements and Financial Worries

(1)

$(2)$

$(3)$

0.280

(0.1840)

0.0915

$(0.1043)$

Not Employed $\quad 0.0815$

$(0.0785)$

Work from home

Work location changed to home

0.000745

$(0.1040)$

Work location remains at home

Absent from work

$-0.0430$

(0.1298)

0.133

(0.1128)
(4)

(5)

(6)

Might lose job

Strongly agree

Agree

Neither agree nor disagree

Disagree

Ability to meet financial obligations

Major impact

Moderate impact

Minor impact

Too soon to tell

Observations

Individual Controls
2433

$\checkmark$

$$
\begin{gathered}
0.224 \\
(0.1250) \\
0.170 \\
(0.1334) \\
0.261 \\
(0.1326) \\
0.117 \\
(0.1113)
\end{gathered}
$$

$\begin{array}{cc}0.0329 & -0.0123 \\ (0.1017) & (0.1038) \\ -0.0955 & -0.113 \\ (0.1319) & (0.1282) \\ 0.132 & -0.00206 \\ (0.1131) & (0.1178)\end{array}$

0.184

(0.1249)

0.163

(0.1337)

0.266

(0.1308)

0.137

(0.1116)

Notes: Authors' calculations. Data from the CPSS. All regressions are estimated using an ordinary least squares estimation with robust standard errors and weights applied. All observations are female. The dependent variable asks individuals their concern about the impact of COVID-19 on family stress due to confinement. The dependent variable takes on the values 1 (Not at all), 2 (Somewhat), 3 (Very), 4 (Extremely). The dependent variable is standardized to have a mean zero and a standard deviation of one. All columns include dummies for age, marital status, whether the dwelling has a child under the age of 18 residing in it, and highest education level attained by the respondent. Each independent variable of interest also contains a "Not stated" category which was controlled for (not shown). Column 1 appends the controls with a categorical variable describing the employment status of the respondent. The base category is "Employed". Column 2 appends the controls with a categorical variable describing if the location of where the respondent worked has changed. The base category is "Work location remains outside the home". Column 3 appends the controls with a categorical variable describing if respondents feel they will lose their main job or main self-employment income in the next 4 weeks. The base category is "Strongly disagree". Observations are fewer because we omit those who are not valid. Column 4 appends the controls with a categorical variable describing if COVID-19 impacted the respondent's ability to meet financial obligations or essential needs. The base category is "No impact". 
Table A4: Standardized Dependent Variable: Concerns about Violence in the Home: Employment, Work Arrangements and Financial Worries

(1)

(2)

(3)

(4)

(5)

(6)

\section{Employment status}

Employed, Absent, not COVID

$-0.0835$

$(0.1306)$

Employed, absent due to COVID $\quad 0.0980$

(0.1460)

Not Employed $\quad-0.0316$

(0.0837)

\section{Work from home}

Work location changed to home

Work location remains at home

Absent from work

Might lose job

Strongly agree

Agree

Neither agree nor disagree

Disagree

Ability to meet financial obligations

Major impact

Moderate impact

Minor impact

Too soon to tell

Observations

Individual Controls
$-0.0775$

(0.1026)

$-0.0273$

(0.1515)

0.0240

(0.1332)
$-0.0571$

(0.1027)

$-0.0262$

(0.1472)

0.0383

(0.1406)

$-0.152$

$-0.0980$

(0.1231)

$-0.0223$

(0.1360)

0.0196

(0.1874)

$-0.200$

(0.1115)

$-0.0722$

(0.1053)

$-0.0626$

(0.1530)

$-0.0466$

(0.1272)

Notes: Authors' calculations. Data from the CPSS. All regressions are estimated using an ordinary least squares estimation with robust standard errors and weights applied. All observations are female. The dependent variable asks individuals their concern about the impact of COVID-19 on violence in the home. The dependent variable takes on the values 1 (Not at all), 2 (Somewhat), 3 (Very), 4 (Extremely). The dependent variable is standardized to have a mean zero and a standard deviation of one. All columns include dummies for age, marital status, whether the dwelling has a child under the age of 18 residing in it, and highest education level attained by the respondent. Each independent variable of interest also contains a "Not stated" category which was controlled for (not shown). Column 1 appends the controls with a categorical variable describing the employment status of the respondent. The base category is "Employed". Column 2 appends the controls with a categorical variable describing if the location of where the respondent worked has changed. The base category is "Work location remains outside the home". Column 3 appends the controls with a categorical variable describing if respondents feel they will lose their main job or main self-employment income in the next 4 weeks. The base category is "Strongly disagree". Observations are fewer because we omit those who are not valid. Column 4 appends the controls with a categorical variable describing if COVID-19 impacted the respondent's ability to meet financial obligations or essential needs. The base category is "No impact". 
Table A5: Standardized Dependent Variable: Concerns about Family Stress: Social Isolation

(1)

$(2)$

(3)

(4)

$(5)$

(6)

\section{Employment status}

Employed, Absent, not COVID $\quad 0.280$

Employed, absent due to COVID 0.0915

(0.1043)

Not Employed $\quad 0.0815$

(0.0785)

Work from home

Work location changed to home

Work location remains at home

Absent from work
0.000745

(0.1040)

$-0.0430$

(0.1298)

0.133

(0.1128)
$-0.00459-0.00108$
$(0.1012) \quad(0.1048)$
$-0.0545 \quad-0.0431$
$(0.1265) \quad(0.1305)$
$0.0282 \quad 0.131$
(0.1107)
$(0.1129)$

\section{Concerned with maintaining Social Ties}

$$
\begin{array}{r}
\text { Somewhat } \\
\text { Very } \\
\text { Extremely }
\end{array}
$$

\section{Communicating with friends and family}

Yes, for my physical health

Yes, for my mental and physical health

No

Observations

Individual Controls

$\begin{array}{cc}0.337 & 0.338 \\ (0.0736) & (0.0732) \\ 0.691 & 0.691 \\ (0.0891) & (0.0889) \\ 1.206 & 1.203 \\ (0.1414) & (0.1409)\end{array}$

-0.0494
$(0.5374)$

$-0.0750$

(0.5436)

0.0348

(0.0699)

0.0361
$(0.0693)$

$-0.0922$

$-0.0890$

$(0.1381)$

2433

2433

2433

2433 $\checkmark$

Notes: Authors' calculations. Data from the CPSS. All regressions are estimated using an ordinary least squares estimation with robust standard errors and weights applied. All observations are female. The dependent variable asks individuals their concern about the impact of COVID-19 on family stress due to confinement. The dependent variable takes on the values 1 (Not at all), 2 (Somewhat), 3 (Very), 4 (Extremely). The dependent variable is standardized to have a mean zero and a standard deviation of one. All columns include dummies for age, marital status, whether the dwelling has a child under the age of 18 residing in it, and highest education level attained by the respondent. Each independent variable of interest also contains a "Not stated" category which was controlled for (not shown). Column 1 appends the controls with a categorical variable describing the employment status of the respondent. The base category is "Employed". Column 2 appends the controls with a categorical variable describing if the location of where the respondent worked has changed. The base category is "Work location remains outside the home". Column 3 appends the controls with a categorical variable describing how concerned the respondents are for maintaining social ties following the impacts of COVID-19. The base category is "Not at all". Column 4 appends the controls with a categorical variable describing if respondents are communicating with friends and family for their health. The base category is "Yes, for my mental health". 
Table A6: Standardized Dependent Variable: Concerns about Violence in the Home: Social Isolation

(1)

$(2)$

(3)

$(4)$

$(5)$

(6)

\section{Employment status}

Employed, Absent, not COVID $\quad-0.0835$

Employed, absent due to COVID $\quad 0.0980$

(0.1460)

Not Employed $\quad-0.0316$

$(0.0837)$

\section{Work from home}

Work location changed to home

Work location remains at home

Absent from work

\section{Concerned with maintaining Social Ties}

Somewhat

Very

Extremely

\section{Communicating with friends and family}

Yes, for my physical health

Yes, for my mental and physical health

No

\section{Observations}

Individual Controls

$\begin{array}{ccc}-0.0775 & -0.0790 & -0.0711 \\ (0.1026) & (0.0993) & (0.1027) \\ -0.0273 & -0.0307 & -0.0259 \\ (0.1515) & (0.1549) & (0.1521) \\ 0.0240 & -0.0374 & 0.0303 \\ (0.1332) & (0.1376) & (0.1327)\end{array}$

$\begin{array}{cc}0.216 & 0.216 \\ (0.0664) & (0.0659) \\ 0.336 & 0.336 \\ (0.0836) & (0.0843) \\ 0.759 & 0.759 \\ (0.1742) & (0.1760)\end{array}$

0.216

0.336

0.759

$(0.1760)$

\begin{tabular}{ccc}
-0.00174 & & -0.0128 \\
$(0.2818)$ & & $(0.2938)$ \\
0.00277 & & -0.00377 \\
$0.0752)$ & & $(0.0756)$ \\
0.146 & & 0.149 \\
$0.1593)$ & & $(0.1589)$ \\
& & \\
2429 & 2429 & 2429 \\
$\checkmark$ & $\checkmark$ & $\checkmark$ \\
\hline
\end{tabular}

Notes: Authors' calculations. Data from the CPSS. All regressions are estimated using an ordinary least squares estimation with robust standard errors and weights applied. All observations are female. The dependent variable asks individuals their concern about the impact of COVID-19 on violence in the home. The dependent variable takes on the values 1 (Not at all), 2 (Somewhat), 3 (Very), 4 (Extremely). The dependent variable is standardized to have a mean zero and a standard deviation of one. All columns include dummies for age, marital status, whether the dwelling has a child under the age of 18 residing in it, and highest education level attained by the respondent. Each independent variable of interest also contains a "Not stated" category which was controlled for (not shown). Column 1 appends the controls with a categorical variable describing the employment status of the respondent. The base category is "Employed". Column 2 appends the controls with a categorical variable describing if the location of where the respondent worked has changed. The base category is "Work location remains outside the home". Column 3 appends the controls with a categorical variable describing how concerned the respondents are for maintaining social ties following the impacts of COVID-19. The base category is "Not at all". Column 4 appends the controls with a categorical variable describing if respondents are communicating with friends and family for their health. The base category is "Yes, for my mental health". 
Table A7: Standardized Dependent Variable: Receiving Financial Relief

(1)

$(2)$

(3)

(4)

(5)

\section{Receiving financial relief}

$\begin{array}{ccccccc}\text { Yes } & 0.328 & 0.316 & 0.255 & 0.203 & 0.198 & 0.156 \\ & (0.1592) & (0.1584) & (0.1610) & (0.1671) & (0.1690) & (0.1668) \\ \text { Not required } & -0.0437 & -0.0426 & 0.0902 & 0.0503 & 0.0577 & 0.124 \\ & (0.0663) & (0.0681) & (0.0698) & (0.0696) & (0.0703) & (0.0736)\end{array}$

\section{Work from home}

Work location changed to home

Work location remains at home

Absent from work

\section{Ability to meet financial obligations}

Major impact

Moderate impact

Minor impact

Too soon to tell

\begin{tabular}{|c|c|c|c|c|}
\hline $\begin{array}{c}0.0133 \\
(0.1031)\end{array}$ & $\begin{array}{l}-0.0105 \\
(0.1028)\end{array}$ & & $\begin{array}{l}-0.0746 \\
(0.1018)\end{array}$ & $\begin{array}{l}-0.0764 \\
(0.1041)\end{array}$ \\
\hline $\begin{array}{c}-0.0349 \\
(0.1313)\end{array}$ & $\begin{array}{c}-0.103 \\
(0.1280)\end{array}$ & & $\begin{array}{l}-0.0176 \\
(0.1511)\end{array}$ & $\begin{array}{l}-0.0577 \\
(0.1502)\end{array}$ \\
\hline $\begin{array}{c}0.113 \\
(0.1142)\end{array}$ & $\begin{array}{c}-0.00506 \\
(0.1167)\end{array}$ & & $\begin{array}{c}0.0226 \\
(0.1342)\end{array}$ & $\begin{array}{l}-0.0486 \\
(0.1277)\end{array}$ \\
\hline & $\begin{array}{c}0.536 \\
(0.1191)\end{array}$ & & & $\begin{array}{c}0.337 \\
(0.1556)\end{array}$ \\
\hline & $\begin{array}{c}0.420 \\
(0.1087)\end{array}$ & & & $\begin{array}{c}0.158 \\
(0.1134)\end{array}$ \\
\hline & $\begin{array}{c}0.220 \\
(0.0991)\end{array}$ & & & $\begin{array}{c}0.0788 \\
(0.1055)\end{array}$ \\
\hline & $\begin{array}{c}0.274 \\
(0.0862)\end{array}$ & & & $\begin{array}{c}0.0484 \\
(0.0952)\end{array}$ \\
\hline 2433 & 2433 & 2429 & 2429 & 2429 \\
\hline$\checkmark$ & $\checkmark$ & $\checkmark$ & $\checkmark$ & $\checkmark$ \\
\hline
\end{tabular}

Observations

Individual Controls

2433

$\checkmark$

Notes: Authors' calculations. Data from the CPSS. All regressions are estimated using an ordinary least squares estimation with robust standard errors and weights applied. All observations are female. The dependent variable in columns 1 to 3 asks individuals their concern about the impact of COVID-19 on family stress due to confinement. The dependent variable takes on the values 1 (Not at all), 2 (Somewhat), 3 (Very), 4 (Extremely). The dependent variables are standardized to have a mean zero and a standard deviation of one. The dependent variable in columns 4 to 6 asks individuals their concern about the impact of COVID-19 on violence in the home. The dependent variable takes on the values 1 (Not at all), 2 (Somewhat), 3 (Very), 4 (Extremely). Those who were assigned to the "Not stated" category in the dependent variable were omitted. All columns include dummies for age, marital status, whether the dwelling has a child under the age of 18 residing in it, and highest education level attained by the respondent. Each independent variable of interest also contains a "Not stated" category which was controlled for (not shown). Column 1 appends the controls with a categorical variable describing if respondents received financial relief for financial obligations. The base category is "No". Column 2 appends the controls with a categorical variable describing if respondents received financial relief for financial obligations. The base category is "No" and with a categorical variable describing if the location of where the respondent worked has changed. The base category is "Work location remains outside the home". Column 3 appends the controls with a categorical variable describing if respondents received financial relief for financial obligations. The base category is "No"; a categorical variable describing if the location of where the respondent worked has changed. The base category is "Work location remains outside the home" and categorical variable describing if COVID-19 impacted the respondent's ability to meet financial obligations or essential needs. The base category is "No impact". Columns 4 to 6 repeat the same specifications of columns 1 to 3 but the dependent variable is now women's concern about the impact of COVID-19 on violence in the home. 
(1)

$-0.145$

(0.094)

$-0.365$

(0.091)

Marital status

Living common-law

$-0.180$

(0.108)

Widowed/Separated/Divorced

$-0.086$

(0.099)

Single, never married

0.259

(0.093)

\section{Child under 18 present in dwelling}

Child under 18 as of March 29th, 2020 resides in dwelling

\section{Highest level of education ever completed}

High school diploma or a high school equivalency certificate

Trade certificate or diploma

$-0.280$

$-0.562$

College/CEGEP/other non-university certificate or

diploma

University certificate or diploma below the

bachelor's level

Bachelor's degree (e.g. B.A., B.Sc., LL.B.)

University certificate, diploma, degree above the

BA level

Observations

Individual Controls

Notes: Authors' calculations. Data from the CPSS. All regressions are estimated using an ordered probit with robust standard errors and weights applied. All observations are female. The dependent variable asks individuals their concern about the impact of COVID-19 on family stress due to confinement. The dependent variable takes on the values 1 (Not at all), 2 (Somewhat), 3 (Very), 4 (Extremely). Column 1 includes dummies for age category. The base category is "15 to 34 ". Column 2 includes dummies for marital status. The base category is "Married". Column 3 includes a dummy for whether the dwelling has a child under the age of 18 residing in it. The base category is "No child under 18 in dwelling". Column 4 includes dummies for the highest level of education attained by the respondent. The base category is "Less than high school diploma or its equivalent". 
Table A9: Violence in the Home: Demographic Individual-Level Controls

(1)

0.043

$(0.124)$

$55+$

\section{Age category}

35 to 54

0.039

$(0.121)$

\section{Marital status}

Living common-law

Widowed/Separated/Divorced

Single, never married

\section{Child under 18 present in dwelling}

Child under 18 as of March 29th, 2020 resides in dwelling

\section{Highest level of education ever completed}

High school diploma or a high school equivalency certificate

Trade certificate or diploma

College/CEGEP/other non-university certificate or diploma

(2)

(3)

(4)
0.310

(0.126)

0.214

(0.1434)

0.211

(0.122)
0.048

(0.106)

$-0.159$

0.055

$(0.213)$

$-0.165$

University certificate or diploma below the

bachelor's level

Bachelor's degree (e.g. B.A., B.Sc., LL.B.)

(0.1901)

0.039

$-0.134$

University certificate, diploma, degree above the

BA level

Observations

Notes: Authors' calculations. Data from the CPSS. All regressions are estimated using an ordered probit with robust standard errors and weights applied. All observations are female. The dependent variable asks individuals their concern about the impact of COVID-19 on violence in the home. The dependent variable takes on the values 1 (Not at all), 2 (Somewhat), 3 (Very), 4 (Extremely). Column 1 includes dummies for age category. The base category is " 15 to 34 ". Column 2 includes dummies for marital status. The base category is "Married". Column 3 includes a dummy for whether the dwelling has a child under the age of 18 residing in it. The base category is " No child under 18 in dwelling". Column 4 includes dummies for the highest level of education attained by the respondent. The base category is "Less than high school diploma or its equivalent". 